\title{
Cost estimation and economical evaluation of three configurations of activated sludge process for a wastewater treatment plant (WWTP) using simulation
}

\author{
Shahryar Jafarinejad ${ }^{1}$
}

Received: 26 November 2015 / Accepted: 30 June 2016/Published online: 8 July 2016

(c) The Author(s) 2016. This article is published with open access at Springerlink.com

\begin{abstract}
The activated sludge (AS) process is a type of suspended growth biological wastewater treatment that is used for treating both municipal sewage and a variety of industrial wastewaters. Economical modeling and cost estimation of activated sludge processes are crucial for designing, construction, and forecasting future economical requirements of wastewater treatment plants (WWTPs). In this study, three configurations containing conventional activated sludge (CAS), extended aeration activated sludge (EAAS), and sequencing batch reactor (SBR) processes for a wastewater treatment plant in Tehran city were proposed and the total project construction, operation labor, maintenance, material, chemical, energy and amortization costs of these WWTPs were calculated and compared. Besides, effect of mixed liquor suspended solid (MLSS) amounts on costs of WWTPs was investigated. Results demonstrated that increase of MLSS decreases the total project construction, material and amortization costs of WWTPs containing EAAS and CAS. In addition, increase of this value increases the total operation, maintenance and energy costs, but does not affect chemical cost of WWTPs containing EAAS and CAS.
\end{abstract}

Keywords Activate sludge $\cdot$ Treatment $\cdot$ Cost $\cdot$ Modeling

Shahryar Jafarinejad

jafarinejad83@gmail.com

1 Department of Environmental Engineering, College of Environment, UoE, Karaj, Iran

\section{Introduction}

Wastewater treatment plants (WWTPs) are complex systems which include a large number of biological, physicochemical, and biochemical processes (Sotomayor et al. 2001). The activated sludge process is the most widely applied biological treatment of liquid waste, treating both municipal sewage and a variety of industrial wastewaters (Aguilar-López et al. 2013; Sotomayor et al. 2001; Slater 2006). Actually, activated sludge systems are a type of suspended growth biological wastewater treatment in which the degradation and removal of contaminants within the wastewater is performed by microorganisms [bacterial biomass suspension (the activated sludge)] (Evans 2012). Depending on the design and the specific application, an activated sludge wastewater treatment plant can achieve biological nitrogen removal and biological phosphorus removal, plus the removal of organic carbon substances (Aguilar-López et al. 2013; Slater 2006; Evans 2012; Jeppsson 1996; Chachuat et al. 2005; Banadda et al. 2011; Gernaey et al. 2004; Nelson and Sidhu 2009; Bakiri et al. 2012). Many researchers have modeled and simulated the activated sludge process (Evans 2012; Jeppsson 1996; Chachuat et al. 2005; Banadda et al. 2011; Gernaey et al. 2004; Nelson and Sidhu 2009; Bakiri et al. 2012; Abdel Kader 2009). A review on the historical evolution of the activated sludge process can be found in the work of Jeppsson (1996).

A number of modifications to the design and operational conditions of the conventional activated sludge process have been developed for the specific purposes of domestic and industrial wastewater treatment. The conventional activated sludge (CAS) process is designed with a plug flow reactor and continuous influent wastewater. A large number of variations of the conventional activated 
sludge process have been designed to improve system performance by modifying the reactor layout, aeration system, influent pattern, and operational conditions. Some of the more widely used modified activated sludge processes include completely mixed activated sludge, stepfeed activated sludge, extended aeration activated sludge (EAAS), sequencing batch reactor (SBR), oxidation ditch, membrane bioreactor (MBR) processes, etc. (Evans 2012).

Sotomayor et al. (2001) developed a simulation benchmark which represented a continuous flow activated sludge process, in a configuration with pre-denitrification, including the processes of organic matter removal, nitrification and denitrification of domestic effluents, for the unbiased performance evaluation of advanced control methods in wastewater treatment plants. Benedetti et al. $(2006 \mathrm{a}, \mathrm{b})$ illustrated the results of a systematic methodology to evaluate system design/upgrade options which allow the choice of the most appropriate trade-off between cost of measures and effluent quality, and to assess the reliability of a process layout. It is, therefore, a flexible instrument to cope with the flexibility and complexity of integrated water management regulations. Lee et al. (2006) reviewed the modeling and control of biological nutrient removal (BNR)-activated sludge processes for wastewater treatment using distributed parameter models described by partial differential equations (PDE). Dynamic optimization is a powerful tool for assisting engineers in determining optimal operations and designs for activated sludge processes. Hreiz et al. (2015) reviewed the literature devoted to optimal control and design of activated sludge processes. Karpinska and Bridgeman (2016) reviewed computational fluid dynamics (CFD)-aided modeling of activated sludge systems in which the rationale behind the use of CFD to model aeration, facilitating enhancement of treatment efficiency and reduction of energy input were discussed.

In the field of wastewater treatment, there is an increasing requirement to improve effluent quality for the benefit of receiving surface waters. Additionally, it is required to minimize energy consumption and reduce the use of chemicals in the treatment process (Meijer 2004). Besides, economical simulation and cost estimation of activated sludge processes are crucial for designing of wastewater treatment plant. Actually, cost estimation provides a powerful tool for design, construction and forecast of future economical requirements. In this study, three configurations for a wastewater treatment plant in Tehran city were proposed and the total project construction, total operation labor, total maintenance labor, total material, total chemical, total energy and total amortization costs of these configurations (plants) were calculated and compared.

\section{Materials and methods}

\section{Influent wastewater}

The investigated municipal wastewater treatment plant in this study is located in Tehran, Iran. The information of this plant was obtained from Mohagheghian et al.'s (2014) work. The biological treatment of this plant is extended aeration activated sludge. It serves 42,000 people. The characteristics of influent wastewater are given in Table 1. In this table, the sludge retention time (SRT), mean influent flow, mean influent COD, mean influent BOD, mean influent SS and average summer temperature of this plant are shown which were obtained from Mohagheghian et al. (2014). In addition, values of minimum influent flow, maximum influent flow, \%volatile solids, soluble COD, soluble BOD, total Kjeldahl nitrogen (TKN), soluble TKN, ammonia, total phosphorus, $\mathrm{pH}$, cations, anions, settleable solids, oil and grease, nondegradable fraction of VSS and average winter temperature were assumed by the author for cost estimation.

\section{Description of WWTP containing EAAS process}

Extended aeration activated sludge is a low-rate activated sludge process operating at low organic loading rates and

Table 1 The characteristics of influent wastewater

\begin{tabular}{ll}
\hline Parameter & Value \\
\hline SRT (days) & $15-20$ \\
Mean influent flow $\left(\mathrm{m}^{3} / \mathrm{h}\right)$ & 200 \\
Minimum influent flow $\left(\mathrm{m}^{3} / \mathrm{h}\right)$ & 100 \\
Maximum influent flow $\left(\mathrm{m}^{3} / \mathrm{h}\right)$ & 300 \\
Mean influent COD $(\mathrm{mg} / \mathrm{L})$ & 304 \\
Soluble COD $(\mathrm{mg} / \mathrm{L})$ & 180 \\
Mean influent BOD $(\mathrm{mg} / \mathrm{L})$ & 130 \\
Soluble BOD $(\mathrm{mg} / \mathrm{L})$ & 60 \\
Mean influent SS (mg/L) & 230 \\
Volatile solids $(\%)$ & 75 \\
Average summer temperature $\left({ }^{\circ} \mathrm{C}\right)$ & $25.7(\sim 26)$ \\
Average winter temperature $\left({ }^{\circ} \mathrm{C}\right)$ & 10 \\
Total Kjeldahl nitrogen $(\mathrm{TKN})(\mathrm{mg} \mathrm{N} / \mathrm{L})$ & 40 \\
Soluble TKN (mg N/L) & 28 \\
Ammonia (mg N/L) & 25 \\
Total phosphorus (mg P/L) & 8 \\
pH & 7.6 \\
Cations (mg/L) & 160 \\
Anions (mg/L) & 160 \\
Settleable solids (mL/L) & 10 \\
Oil and grease (mg/L) & 100 \\
Non-degradable fraction of VSS $(\%)$ & 40 \\
\hline
\end{tabular}




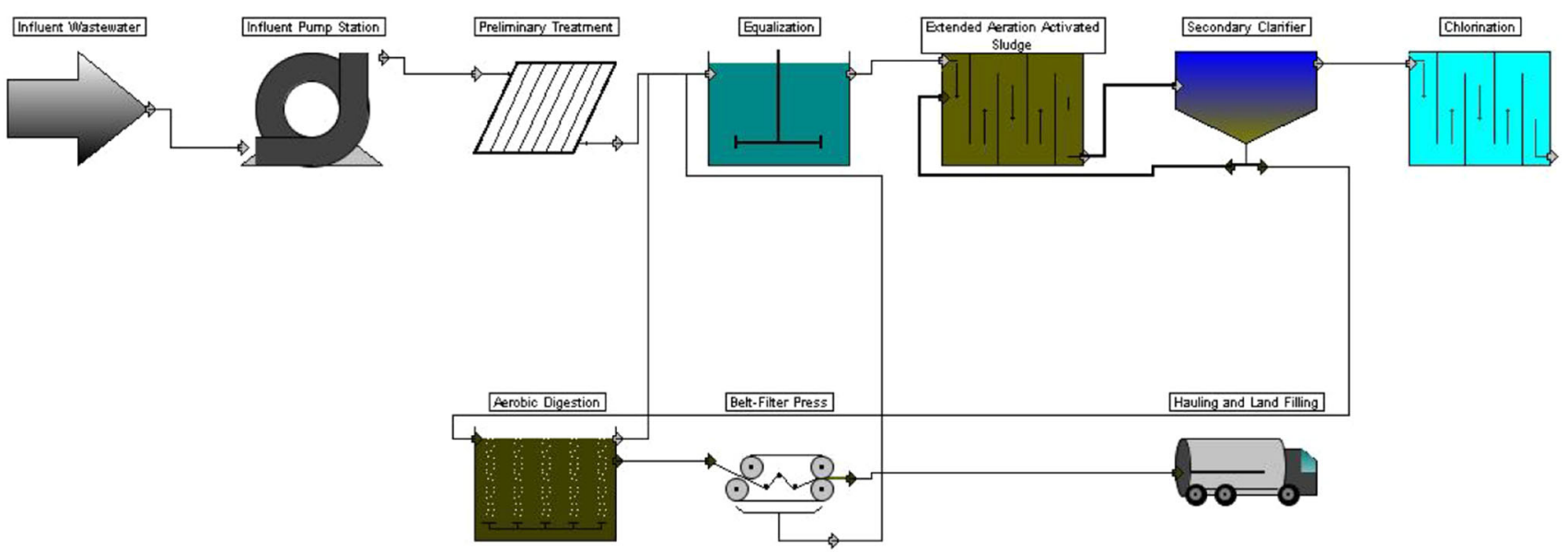

Fig. 1 Layout of wastewater treatment plant containing EAAS process

F/M ratios with long hydraulic retention times and sludge ages. As a result, there is little food in the system to support the microorganisms present. Competition is active and high-quality outflows are produced. It is usually used without primary settlement and nitrification is normally achieved. Extended aeration plants are often used as package plants for small communities (EPA 1997).

Layout of wastewater treatment plant containing EAAS process is shown in Fig. 1. This plant consists of influent pump station, preliminary treatment (screening, grit removal), equalization, extended aeration activated sludge, secondary clarifier, chlorination, aerobic digestion, belt-filter press, and hauling and land filing. This plant requires equalization tank to regulate the flow. Influent pump station consists of three constant speed pumps with static head $12.192 \mathrm{~m}$. Cleaning method in screening is mechanical and average velocity is $0.762 \mathrm{~m} / \mathrm{s}$. Width, space, slope and shape factor of bars are $0.63 \mathrm{~cm}, 3.8 \mathrm{~cm}, 30^{\circ}$ and 2.42 , respectively. Type of grit removal is horizontal with surface velocity and tank floor velocity of 0.45 and $0.3 \mathrm{~m} / \mathrm{s}$, respectively. Particle size, specific gravity, number of units, depth, manning coefficient, volume of grit, detention time and air supply per unit length of tank in grit removal are $0.02 \mathrm{~cm}, 2.65,2,1.2 \mathrm{~m}, 0.035,3 \times 10^{-5} \mathrm{~m}^{3} \mathrm{grit} / \mathrm{m}^{3}$, $2.5 \mathrm{~min}$ and $0.28 \mathrm{~N} \mathrm{~m}^{3} / \mathrm{min} / \mathrm{m}$, respectively. Oxygen requirements, pressure correction coefficient, dissolved oxygen, basin type, depth of basin, minimum water level in equalization, alpha factor for oxygen transfer in wastewater, beta factor for oxygen saturation in wastewater, minimum hp requirement for mixing and standard oxygen transfer efficiency in mechanical aeration of equalization are $15 \mathrm{mg} /$ (Llh), 1, $2 \mathrm{mg} / \mathrm{L}$, concrete basin, $1.82 \mathrm{~m}, 1.52 \mathrm{~m}, 0.9,0.95$, $11.81 \mathrm{~W} / \mathrm{m}^{3}$ and $3.04 \mathrm{~kg} \mathrm{O}_{2} / \mathrm{kWh}$, respectively. The characteristics of EAAS process are given in Table 2. Type of secondary clarifier is circular and surface overflow rate, side water depth, specific gravity, underflow concentration, weir
Table 2 The characteristics of EAAS process

\begin{tabular}{ll}
\hline Parameter & Value \\
\hline SRT (day) & 20 \\
Mixed liquor suspended solids (MLSS) (mg/L) & 2500 \\
Maximum heterotrophic-specific growth rate & 6 \\
$\quad(1 /$ day) & \\
Heterotrophic decay rate (1/day) & 0.24 \\
Maximum autotrophic-specific growth rate (1/day) & 0.5 \\
Autotrophic decay rate (1/day) & 0.04 \\
Biomass yield & 0.5 \\
Aeration type & Diffusion \\
& \multicolumn{1}{c}{ aeration } \\
Bubble size & Fine \\
Alpha factor for oxygen transfer in wastewater & 0.5 \\
Beta factor for oxygen saturation in wastewater & 0.95 \\
Fine bubble minimum air flow (L/s/m $\left.{ }^{2}\right)$ & 0.61 \\
Standard oxygen transfer efficiency $(\%)$ & 20 \\
\hline
\end{tabular}

overflow rate-maximum and effluent suspended solids are $20.37 \mathrm{~m}^{3} /\left(\mathrm{m}^{2}\right.$ day $), 2.74 \mathrm{~m}, 1.03,1 \%, 186.3 \mathrm{~m}^{3} /(\mathrm{m}$ day $)$ and $10 \mathrm{mg} / \mathrm{L}$, respectively. Contact time at peak flow, chlorine dose and influent coliform count in chlorination are $30 \mathrm{~min}, 10 \mathrm{mg} / \mathrm{L}$ and $10^{7} / 100 \mathrm{~mL}$, respectively. Detention time, volatile solids destroyed, mixed liquor solids, digested sludge concentration and temperature in aerobic digestion are 18 days, $40 \%, 12,000 \mathrm{mg} / \mathrm{L}, 2.5 \%$ and $23{ }^{\circ} \mathrm{C}$, respectively. Aeration type in aerobic digestion is diffusion aeration and alpha factor for oxygen transfer in wastewater, beta factor for oxygen saturation in wastewater, coarse bubble minimum air flow and standard oxygen transfer efficiency are $0.7,0.95,0.33 \mathrm{~L} / \mathrm{s} / \mathrm{m}^{3}$ and $6 \%$, respectively. Suspended solids, BOD, COD, TKN and ammonia in supernatant of aerobic digestion are $3400 \mathrm{mg} / \mathrm{L}, 500 \mathrm{mg} / \mathrm{L}, 2600 \mathrm{mg} / \mathrm{L}$, $17 \mathrm{mg} \mathrm{N} / \mathrm{L}$ and $0 \mathrm{mg} / \mathrm{L}$, respectively. Cake solids content, 
density of cake, operating schedule per day, days operating per week, hydraulic loading per meter of belt press width, polymer dose and filtrate solid concentration in belt-filter press are $19 \%, 1201.4 \mathrm{~kg} / \mathrm{m}^{3}, 8 \mathrm{~h} /$ day, 5 days/week, $381.6 \mathrm{~m}^{3} /$ day, $1 \%$ dry wt and $100 \mathrm{mg} / \mathrm{L}$, respectively. Disposal cost is based on annual charge of land fill and distance to disposal site, daily operation, loading time per vehicle, and hauling time per trip in hauling and land filling are $16 \mathrm{~km}, 8 \mathrm{~h}, 0.75 \mathrm{~h}$ and $1 \mathrm{~h}$, respectively.

It is also assumed that the aerobic digestion (case 1) in this WWTP can be theoretically replaced by anaerobic digestion (case 2) or gravity thickening (case 3 ) or sludge flotation thickening (case 4). The economical details of these suggestions are compared. In anaerobic digestion, specific gravity, percent volatile solids destroyed, concentration in digester, minimum detention time in primary digester, raw wastewater temperature, digester temperature and location of digester are 1.05, 50\%, 5\%, 20 days, $20{ }^{\circ} \mathrm{C}, 40{ }^{\circ} \mathrm{C}$ and moderate-winter $\sim 0{ }^{\circ} \mathrm{C}$, respectively, and fraction of influent flow returned as supernatant, suspended solids, BOD, COD, TKN, ammonia in supernatant are $2 \%, 6250 \mathrm{mg} / \mathrm{L}, 1000 \mathrm{mg} / \mathrm{L}, 2150 \mathrm{mg} / \mathrm{L}, 950 \mathrm{mg} \mathrm{N} / \mathrm{L}$ and $650 \mathrm{mg} / \mathrm{L}$, respectively. Underflow concentration, depth and mass loading in gravity thickening are $5 \%$, $2.74 \mathrm{~m}$ and $48.82 \mathrm{~kg} /\left(\mathrm{m}^{2}\right.$ day $)$, respectively. Air pressure, detention time in float tank, solids loading, hydraulic loading, recycle time in pressure tank, removal of solids, air/solids ratio, float concentration, and polymer required are $413.66 \mathrm{kPa}, 3 \mathrm{~h}, 48.82 \mathrm{~kg} /\left(\mathrm{m}^{2}\right.$ day $), 146.69 \mathrm{~m}^{3} /\left(\mathrm{m}^{2}\right.$ day), $2 \mathrm{~min}, 0.02,4 \%$ and $0.5 \mathrm{~g} / \mathrm{kg}$, respectively.

\section{Description of WWTP containing CAS process}

The conventional (plug flow) activated sludge process uses an aeration tank, a settling tank (clarifier), and a sludge return line to treat wastewater. Wastewater and return sludge from the secondary clarifier enter the head of the aeration tank to undergo a specific period of aeration. The main characteristic of a plug flow configuration is a high ratio of organic loading (i.e., F/M) to the mixed liquor at the beginning of the tank. There is little longitudinal mixing in a plug flow tank except for that which is caused by diffused aeration; therefore, as the liquor flows through its length, substrate is used up and the mass of microorganisms increases due to cell reproduction. If the F/M is sufficiently low in the latter stages of the tank, much of the oxygen is consumed by nitrification and endogenous respiration. The lack of longitudinal mixing reduces the ability to handle shock loads; there is little dilution of the inflow so microorganisms may be affected by toxic material. Plug flow has the advantage of discouraging the excessive growth of filamentous organisms which can cause settlement problems in the secondary settlement tank (EPA 1997).

Layout of wastewater treatment plant containing CAS process is shown in Fig. 2. The proposed plant consists of influent pump station, preliminary treatment (screening, grit removal), primary clarification, conventional (plug flow) activated sludge, secondary clarifier, chlorination, sludge flotation thickening, anaerobic digestion, belt-filter press, and hauling and land filing. The characteristics and operational conditions of influent pump station, preliminary treatment (screening, grit removal), secondary clarifier, chlorination, sludge flotation thickening, anaerobic digestion, belt-filter press, and hauling and land filing are the same as that of WWTP containing EAAS process. Type of primary clarifier is circular and surface overflow rate, side water depth, specific gravity, underflow concentration, weir overflow rate, removal of suspended solids, removal of BOD, removal of COD, removal of TKN, and removal of phosphorus are $40.74 \mathrm{~m}^{3} /\left(\mathrm{m}^{2}\right.$ day $), 2.74 \mathrm{~m}, 1.05,4 \%$, $186.3 \mathrm{~m}^{3} /(\mathrm{m}$ day), 58, 32, 40, 5, and $5 \%$, respectively. Process design of CAS is for removal of carbon plus

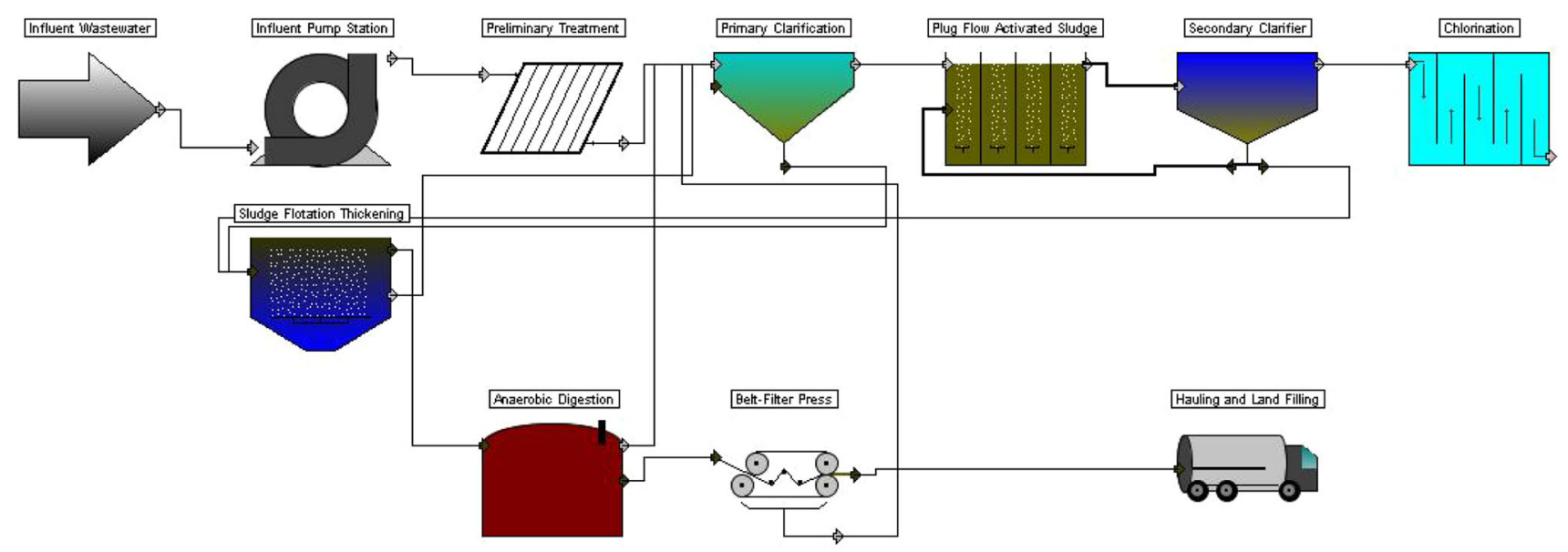

Fig. 2 Layout of wastewater treatment plant containing CAS process 
Table 3 The characteristics of CAS process

\begin{tabular}{ll}
\hline Parameter & Value \\
\hline SRT (day) & 15 \\
Mixed liquor suspended solids (MLSS) (mg/L) & 2500 \\
Maximum heterotrophic-specific growth rate (1/day) & 6 \\
Heterotrophic decay rate (1/day) & 0.24 \\
Maximum autotrophic-specific growth rate (1/day) & 0.5 \\
Autotrophic decay rate (1/day) & 0.04 \\
Biomass yield & 0.5 \\
Aeration type & Diffusion \\
& aeration \\
Bubble size & Fine \\
Alpha factor for oxygen transfer in wastewater & 0.5 \\
Beta factor for oxygen saturation in wastewater & 0.95 \\
Fine bubble minimum air flow (L/s/m ${ }^{2}$ ) & 0.61 \\
Standard oxygen transfer efficiency $(\%)$ & 20 \\
\hline
\end{tabular}

nitrification. The characteristics of CAS process are given in Table 3.

\section{Description of WWTP containing SBR process}

The SBR is a fill-and-draw activated sludge system for wastewater treatment. In this system, wastewater is added to a single batch reactor, treated to remove undesirable components, and then discharged. Equalization, aeration, and clarification can all be achieved using a single batch reactor. To optimize the performance of the system, two or more batch reactors are used in a predetermined sequence of operations. SBR systems can be used to treat both municipal and industrial wastewater. The operation of an SBR is based on a fill-and-draw principle, which consists of five steps: fill, react, settle, draw, and idle. These steps can be altered for different operational applications. SBRs are typically used at flow rates of $219 \mathrm{~L} / \mathrm{s}$ (5 MGD) or less. The more sophisticated operation required at larger SBR plants tends to discourage the use of these plants for large flow rates. The SBR technology is particularly attractive for treating smaller wastewater flows. The majority of plants were designed at wastewater flow rates of less than $22 \mathrm{~L} / \mathrm{s}$ (0.5 MGD). The cost-effectiveness of SBRs may limit their utilization to flows less than 440 L/s (10 MGD) (EPA 1997; Metcalf and Eddy 1991; USEPA 1999; Gurtekin 2014).

Layout of wastewater treatment plant containing SBR process is shown in Fig. 3. The proposed plant consists of influent pump station, preliminary treatment (screening, grit removal), sequencing batch reactor, equalization, filtration, chlorination, sludge flotation thickening, anaerobic digestion, belt-filter press, and hauling and land filing. According to USEPA (2000), an equalization tank is usually required prior to the chlorination unit in batch SBRs to store large volumes of water. When the flow is not equalized, a sizable filter may be necessary to accommodate the large flow of water entering the chlorination system. In addition, SBR systems usually have no primary or secondary clarifiers as settling occurs in the SBR (USEPA 2000). The characteristics and operational conditions of influent pump station, preliminary treatment (screening, grit removal), equalization, chlorination, sludge flotation thickening, anaerobic digestion, belt-filter press, and hauling and land filing are the same as that of WWTPs containing EAAS and CAS processes. Process design of SBR is for removal of carbon plus nitrification. The characteristics of SBR process are given in Table 4. In filtration, loading rate, approach velocity, $60 \%$ finer size, specific weight of sand, porosity of bed, expanded depth, number of trough, width of trough, underdrain depth, head loss in underdrain, operating depth of water above sand, height of trough from underdrain, backwash time, freeboard, and number of layers are $352.05 \mathrm{~m}^{3} /\left(\mathrm{m}^{2}\right.$ day),

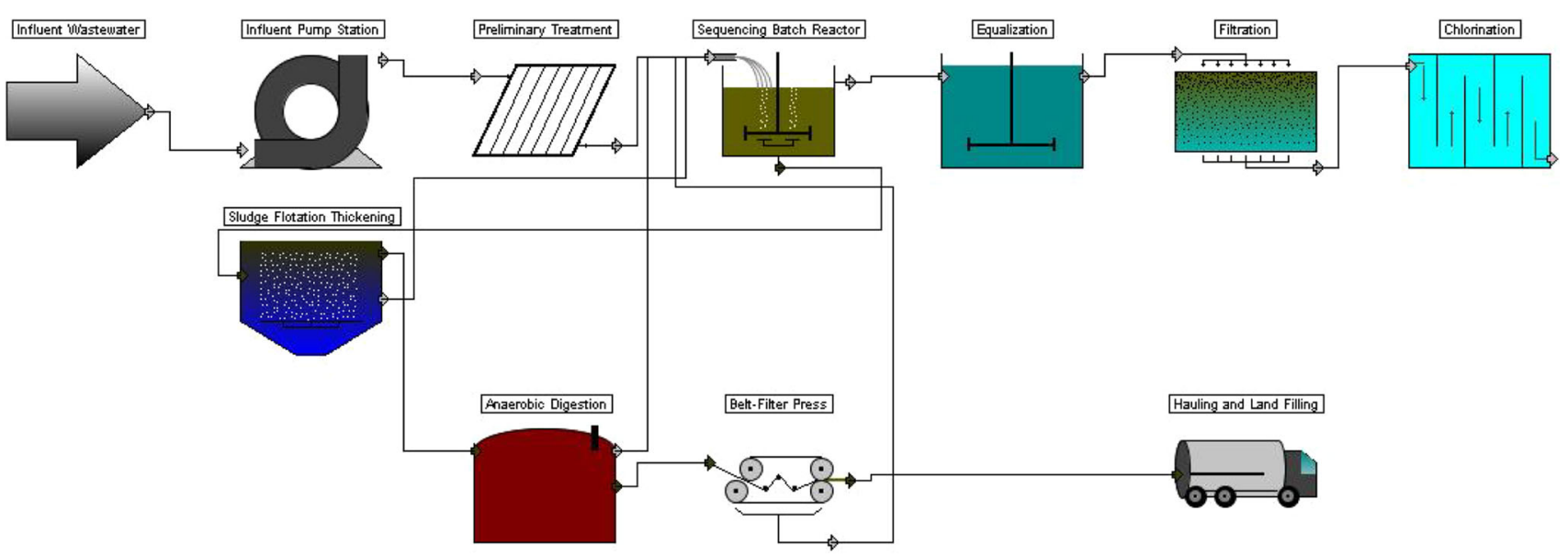

Fig. 3 Layout of wastewater treatment plant containing SBR process 
Table 4 The characteristics of SBR process

\begin{tabular}{ll}
\hline Parameter & Value \\
\hline SRT (day) & 15 \\
Effluent soluble BOD (mg/L) & 8 \\
Effluent total nitrogen (mg N/L) & 10 \\
Effluent total phosphorus (mg P/L) & 1 \\
Maximum heterotrophic-specific growth rate & 6 \\
$\quad$ (1/day) & \\
Heterotrophic decay rate (1/day) & 0.24 \\
Maximum autotrophic-specific growth rate (1/day) & 0.5 \\
Autotrophic decay rate (1/day) & 0.04 \\
Biomass yield & 0.5 \\
Underflow concentration (\%) & 0.8 \\
Decant suspended solids (mg/L) & 25 \\
Aeration period (h) & 4 \\
Unaerated period (h) & 2 \\
Settle and decant time (h) & 1.5 \\
Exchange volume/cycle (\%) & 50 \\
Number of SBRs & 2 \\
Aeration type & Diffusion \\
Bubble size & aeration \\
Alpha factor for oxygen transfer in wastewater, & 0.5 \\
Beta factor for oxygen saturation in wastewater & 0.95 \\
Minimum air flow (L/s/m ${ }^{2}$ ) & 0.333 \\
Standard oxygen transfer efficiency (\%) & 20 \\
\hline
\end{tabular}

Table 5 Details of four layers in filtration

\begin{tabular}{lllll}
\hline Layer & Layer 1 & Layer 2 & Layer 3 & Layer 4 \\
\hline Depth $(\mathrm{m})$ & 0.304 & 0.304 & 0.304 & 0.304 \\
Coefficient of permeability & 6 & 5 & 4 & 6 \\
Porosity & 0.50 & 0.40 & 0.47 & 0.60 \\
Particle diameter $(\mathrm{cm})$ & 0.14 & 0.06 & 0.03 & 1.52 \\
Shape factor & 7 & 8.5 & 8 & 6 \\
Specific gravity & 1.40 & 2.65 & 2.65 & 2.65 \\
\hline
\end{tabular}

$0.15 \mathrm{~cm} / \mathrm{s}, \quad 0.75 \mathrm{~mm}, \quad 2649.5 \mathrm{~kg} / \mathrm{m}^{3}, \quad 0.4, \quad 1.52 \mathrm{~m}, \quad 50$, $0.304 \mathrm{~m}, 0.304 \mathrm{~m}, 0.304 \mathrm{~m}, 0.91 \mathrm{~m}, 1.98 \mathrm{~m}, 10 \mathrm{~min}$, $0.304 \mathrm{~m}$, and 4 , respectively. The details of four layers in filtration are given in Table 5 .

\section{Method}

Using simulation, the planning level design and costing productivity improves dramatically leading to better engineering decisions. Cost estimation to build, operate and

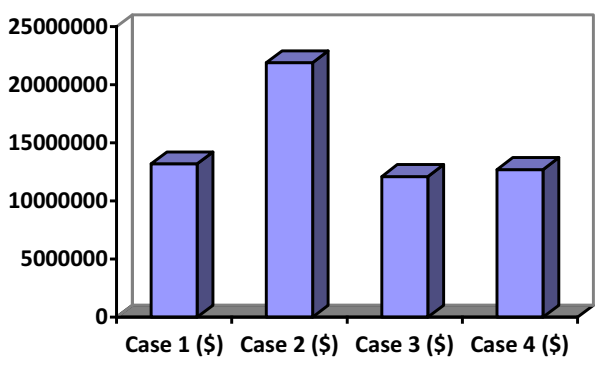

Fig. 4 The total project construction cost (\$) of case 1, case 2, case 3, and case 4

maintain the WWTPs was done using CapdetWorks 2.5 with equipment costing database Sept. 2007 (USA, Avg). CapdetWorks calculates all the costs—capital, operating and maintenance for each treatment alternative.

\section{Results and discussion}

\section{Economical comparison of cases in WWTP containing EAAS process}

The total project construction cost $(\$)$ and the total operation, maintenance, material, chemical, energy, and amortization costs (\$/year) of case 1 , case 2 , case 3 , and case 4 are shown in Figs. 4 and 5, respectively. Figure 4 illustrates that project construction cost of case $3<$ case $4<$ case $1<$ case 2 . The project construction cost of case 2 is $65.9 \%$ higher than that of case 1 and this value for case 1 is $8.33 \%$ higher than that of case 3 . Figure 5 illustrates that operation cost of case $3<$ case $2<$ case $4<$ case 1 , maintenance cost of case $3<$ case $4<$ case $2<$ case 1 , material cost of case $3<$ case $4<$ case $1<$ case 2 , chemical cost of case $1<$ case $3<$ case $4<$ case 2 , energy cost of case $3<$ case $4<$ case $2<$ case 1 and amortization cost of case $3<$ case $4<$ case $1<$ case 2. These results depict that if WWTP requires digestion, use of aerobic digestion will be cost effective and if it does not require digestion and needs thickening, use of gravity thickening will be cost effective.

\section{Economical comparison of WWTPs containing EAAS, CAS, and SBR processes}

The total project construction cost $(\$)$ and the total operation, maintenance, material, chemical, energy, and amortization costs (\$/year) of WWTPs containing EAAS, CAS, and SBR processes are shown in Figs. 6 and 7, respectively. Figure 6 illustrates the project construction cost of WWTP containing CAS $<$ EAAS $<$ SBR. Figure 7 illustrates that operation cost of WWTP containing 

maintenance, material, chemical, energy, and amortization costs (\$/year) of case 1 , case 2 , case 3 , and case 4

Fig. 6 The total project construction cost (\$) of WWTPs containing EAAS, CAS, and SBR processes
Fig. 5 The total operation,
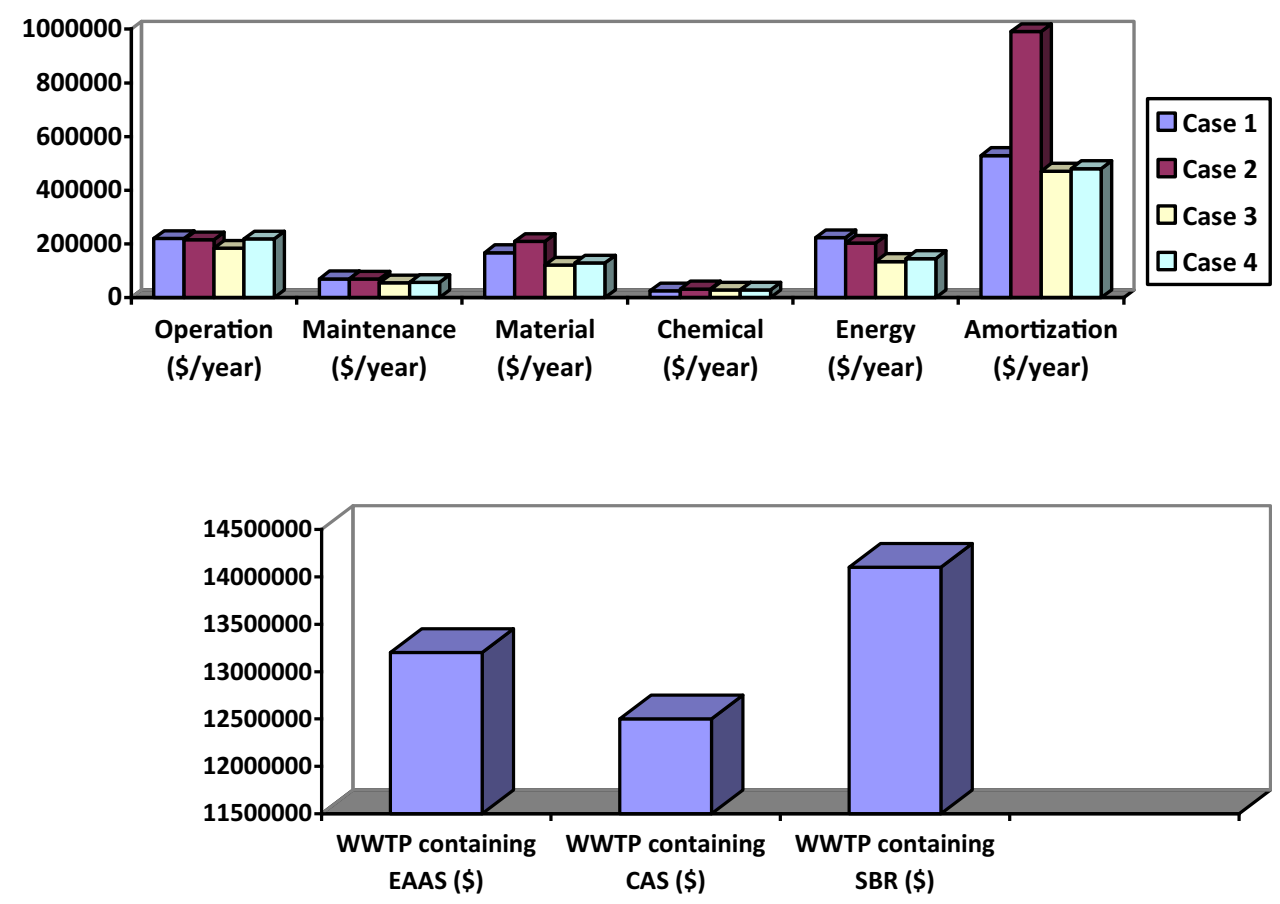

Fig. 7 The total operation, maintenance, material, chemical, energy, and amortization costs (\$/year) of WWTPs containing EAAS, CAS, and SBR processes
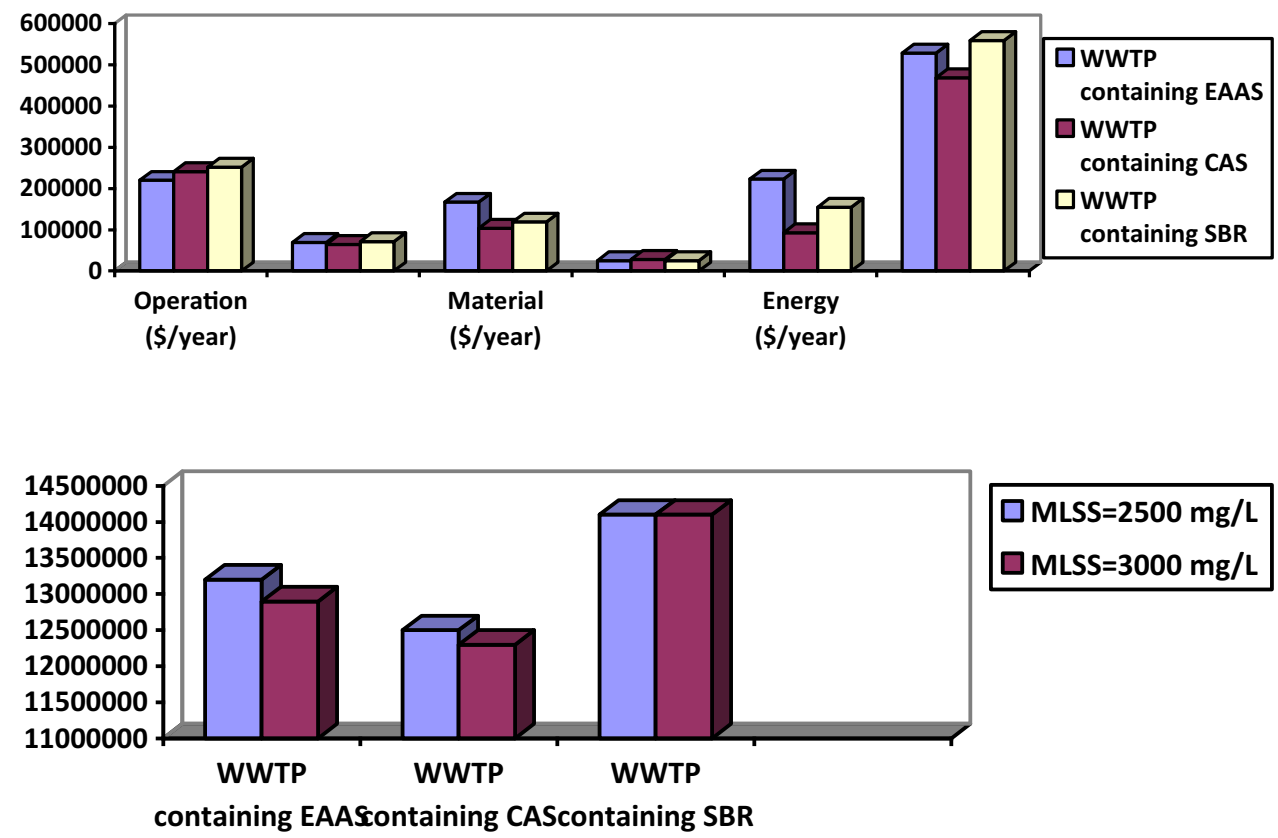

(\$)

(\$)

(\$)
EAAS $<$ CAS $<$ SBR, maintenance cost of WWTP containing CAS $<$ EAAS $<$ SBR, material cost of WWTP containing $\mathrm{CAS}<\mathrm{EAAS}<\mathrm{SBR}$, chemical cost of WWTP containing CAS $=$ SBR $<$ CAS, energy cost of WWTP containing CAS $<$ SBR $<$ EAAS and amortization cost of WWTP containing CAS $<$ EAAS $<$ SBR. These results depict that the WWTP containing CAS process is cost effective.

\section{Effect of MLSS amount on costs of WWTPs containing EAAS, CAS, and SBR processes}

The total project construction cost (\$) of WWTPs containing EAAS, CAS, and SBR processes at different MLSSs are shown in Fig. 8 and the total operation, maintenance, material, chemical, energy, and amortization costs (\$/year) of WWTPs containing EAAS, CAS, and SBR processes at 
Table 6 The total operation, maintenance, material, chemical, energy, and amortization costs (\$/year) of WWTPs containing EAAS, CAS, and SBR processes at different MLSSs

\begin{tabular}{|c|c|c|c|c|c|c|}
\hline WWTP & Operation (\$/year) & Maintenance (\$/year) & Material (\$/year) & Chemical (\$/year) & Energy (\$/year) & Amortization (\$/year) \\
\hline \multicolumn{7}{|l|}{ MLSS $=2500 \mathrm{mg} / \mathrm{L}$} \\
\hline Containing CAS & 241,000 & 64,500 & 104,000 & 28,000 & 93,200 & 469,000 \\
\hline Containing SBR & 252,000 & 71,100 & 119,000 & 24,900 & 155,000 & 559,000 \\
\hline Containing EAAS & 220,000 & 69,400 & 167,000 & 24,900 & 223,000 & 529,000 \\
\hline \multicolumn{7}{|l|}{ MLSS $=3000 \mathrm{mg} / \mathrm{L}$} \\
\hline Containing CAS & 242,000 & 64,900 & 101,000 & 28,000 & 94,700 & 462,000 \\
\hline Containing SBR & 252,000 & 71,100 & 119,000 & 24,900 & 155,000 & 529,000 \\
\hline Containing EAAS & 221,000 & 69,700 & 161,000 & 24,900 & 224,000 & 514,000 \\
\hline
\end{tabular}

different MLSSs are given in Table 6. These results demonstrate that increase of MLSS does not affect costs of WWTP containing SBR, but increase of this value decreases the total project construction, material and amortization costs of WWTPs containing EAAS and CAS. In addition, increase of this value increases the total operation, maintenance and energy costs, but does not affect chemical cost of WWTPs containing EAAS and CAS.

\section{Conclusions}

Three configurations for a wastewater treatment plant in Tehran city were proposed and the total project construction, operation, maintenance, material, chemical, energy and amortization costs of these WWTPs were calculated and compared. Results illustrated that project construction cost of WWTP containing CAS $<$ EAAS $<$ SBR, operation cost of WWTP containing EAAS $<\mathrm{CAS}<\mathrm{SBR}$, maintenance cost of WWTP containing $\mathrm{CAS}<\mathrm{E}$ AAS $<$ SBR, material cost of WWTP containing CAS $<$ EAAS $<$ SBR, chemical cost of WWTP containing $\mathrm{CAS}=\mathrm{SBR}<\mathrm{CAS}$, energy cost of WWTP containing $\mathrm{CAS}<\mathrm{SBR}<\mathrm{EAAS}$ and amortization cost of WWTP containing CAS $<$ EAAS $<\mathrm{SBR}$. These results depicted that the WWTP containing CAS process is cost effective. Besides, increase of MLSS does not affect costs of WWTP containing SBR, but increase of this value decreases the total project construction, material and amortization costs of WWTPs containing EAAS and CAS. In addition, increase of this value increases the total operation, maintenance and energy costs, but does not affect chemical cost of WWTPs containing EAAS and CAS.

Open Access This article is distributed under the terms of the Creative Commons Attribution 4.0 International License (http:// creativecommons.org/licenses/by/4.0/), which permits unrestricted use, distribution, and reproduction in any medium, provided you give appropriate credit to the original author(s) and the source, provide a link to the Creative Commons license, and indicate if changes were made.

\section{References}

Abdel Kader AM (2009) Comparison study between sequencing batch reactors and conventional activated sludge by using simulation mathematical model. In: Thirteenth international water technology conference, IWTC 13 2009, Hurghada, Egypt

Aguilar-López R, López-Pérez PA, Peña-Caballero V, Maya-Yescas R (2013) Regulation of an activate sludge wastewater plant via robust active control design. Int J Environ Res 7:61-68

Bakiri Z, Chebli D, Nacef S (2012) Dynamic modelling of the secondary settler of a wastewater treatment via activated sludge to low-load. Energy Procedia 18:1-9

Banadda N, Nhapi I, Kimwaga R (2011) A review of modeling approaches in activated sludge systems. Afr $\mathrm{J}$ Environ Sci Technol 5:397-408

Benedetti L, Bixio D, Vanrolleghem PA (2006a) Benchmarking of WWTP design by assessing costs, effluent quality and process variability. Water Sci Technol 54:95-102

Benedetti L, Bixio D, Vanrolleghem PA (2006b) Assessment of WWTP design and upgrade options: balancing costs and risks of standards' exceedance. Water Sci Technol 54:371-378

Chachuat B, Roche N, Lafiti MA (2005) Optimal aeration control of industrial alternating activated sludge plants. Biochem Eng J 23:277-289

Environmental Protection Agency (1997) Waste water treatment manuals, primary, secondary and tertiary treatment. Ardcavan, Wexford

Evans RW (2012) Implementing an improved activated sludge model into modeling software. MS thesis, Environmental Systems Engineering, University of Regina

Gernaey KV, van Loosdrecht MCM, Henze M, Lind M, Jørgensen SB (2004) Activated sludge wastewater treatment plant modelling and simulation: state of the art. Environ Model Softw 19:763-783

Gurtekin E (2014) Sequencing batch reactor, Akademik Platform. In: ISEM 2014, Adiyaman. http://i-sem.info/PastConferences/ ISEM2014/ISEM2014/papers/A3-ISEM2014ID81.pdf

Hreiz R, Latifi MA, Roche N (2015) Optimal design and operation of activated sludge processes: state-of-the-art. Chem Eng J 281:900-920

Jeppsson U (1996) Modelling aspects of wastewater treatment processes. PhD thesis, IEA, Lund Institute of Technology, Lund 
Karpinska AM, Bridgeman J (2016) CFD-aided modelling of activated sludge systems - a critical review. Water Res $88: 861-879$

Lee TT, Wang FY, Newell RB (2006) Advances in distributed parameter approach to the dynamics and control of activated sludge processes for wastewater treatment. Water Res 40:853-869

Meijer SCF (2004) Theoretical and practical aspects of modeling activated sludge processes. Department of Biotechnological Engineering, Kluyver Laboratory for Biotechnology, Delft University of Technology, the Netherlands, Giethoorn ten Brink BV, Meppel, The Netherlands. http://repository.tudelft.nl/view/ ir/uuid\%3Ae0d5af2b-7bf6-4cd8-9a22-aac3f8d112fe/

Mohagheghian A, Nabizadeh R, Mesdghinia A, Rastkari N, Mahvi AH, Alimohammadi M, Yunesian M, Ahmadkhaniha R, Nazmara S (2014) Distribution of estrogenic steroids in municipal wastewater treatment plants in Tehran, Iran. J Environ Health Sci Eng 12:1-7

Nelson MI, Sidhu HS (2009) Analysis of the activated sludge model (number 1). Appl Math Lett 22:629-635
Slater N (2006) Sequencing batch reactors: cost effective wastewater treatment. In: Alberta water and wastewater operators association 32nd annual operators seminar, 16 March 2006, Banff, Alberta

Sotomayor OAZ, Park SW, Garcia C (2001) A simulation benchmark to evaluate the performance of advanced control techniques in biological wastewater treatment plants. Braz J Chem Eng 18:81-101

Tchobanoglous G, Burton FL (1991) Wastewater engineering, treatment, disposal and reuse. In: Tchobanoglous G, Burton FL, Metcalf and Eddy Inc. (eds) Water resources and environmental engineering, 3rd edn. Mc Graw-Hill, New York

USEPA (1999) Wastewater, technology fact sheet: sequencing batch reactors. U.S. Environmental Protection Agency, Office of Water, Washington (EPA 932-F-99-073)

USEPA (2000) Wastewater, technology fact sheet: package plants. U.S. Environmental Protection Agency, Office of Water, Washington EPA 832-F-00-016 